\title{
Healthy Eating for Elders: Drink to Your Health ${ }^{1}$
}

\section{Jennifer Hillan ${ }^{2}$}

For the following shakes and smoothies, blend all ingredients until smooth and creamy. If you use frozen $\sim^{\circ}$ fruit, no ice is needed. Otherwise, m. blend with 2 ice cubes. Enjoy!

\section{Strawberry Shake \\ 1 cup buttermilk \\ $1 / 2$ cup strawberries \\ (fresh or frozen) \\ $1 / 4$ cup cranberry juice \\ 2 tbsp wheat germ}

\section{Berry Banana Smoothie}

1 cup low-fat plain yogurt

$1 / 2$ cup blueberries (fresh or frozen)

$1 / 2$ banana (fresh or frozen)

2 tbsp wheat germ

\section{Peachy Smoothie}

1 cup low-fat vanilla yogurt

$1 / 2$ cup sliced peaches

(fresh, frozen, or canned)

$1 / 4$ cup orange juice

2 tbsp wheat germ

\section{Peanut Butter Banana Shake}

1 cup low-fat milk

1 banana (fresh or frozen)

1 tbsp creamy peanut butter

1 tsp vanilla extract

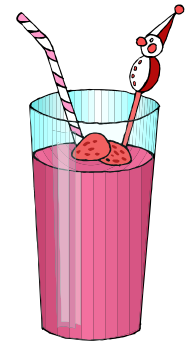

of Tip: Peel ripe bananas, slice, and store in freezer up to 2 weeks.

\section{Chocolate Banana Shake \\ 1 cup low-fat milk \\ 1 banana (fresh or frozen) \\ 3 tbsp powdered cocoa}

\section{Apple Pie Smoothie}

1 cup low-fat vanilla yogurt

$1 / 4$ cup apple juice

$1 / 2$ apple

$1 / 4$ cup unsweetened applesauce

$1 / 4$ tsp ground cinnamon

$1 / 4$ tsp ground nutmeg



Tropical Shake

1 cup buttermilk

$1 / 2$ mango

$1 / 2$ cup pineapple (fresh or canned)

1 tsp vanilla extract

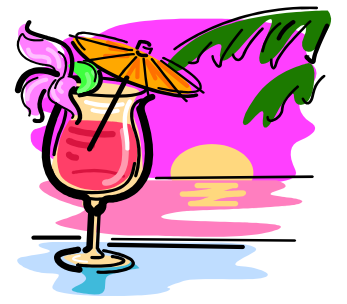

If you are lactose intolerant, substitute calciumfortified soy or rice milk instead of cow's milk.

\footnotetext{
1. This document, FCS8694-Eng, is one in a series of the Department of Family, Youth and Community Sciences, Florida Cooperative Extension Service, Institute of Food and Agricultural Sciences, University of Florida, Gainesville, FL 32611. Publication date: March 2004. This leaflet was developed with funding from the Florida Department of Elder Affairs in partnership with state, county, and local agencies. Please visit the EDIS Web site at http://edis.ifas.ufl.edu 